\title{
Analyzing ancient Chinese handmade Lajian paper exhibiting an orange-red color
}

\author{
Yanbing Luo ${ }^{1 *}$, Jiali Chen ${ }^{1}$, Cheng Yang ${ }^{2}$ and Yifan Huang ${ }^{3}$
}

\begin{abstract}
The ancient technique employed to produce Lajian paper — a very famous Chinese traditional handmade paperhas been lost. However, widespread restoration of the traditional skills used in the paper's production is emerging in China. A small piece of orange-red Lajian paper dating from the Qing dynasty and decorated with flecked Ag and Au was chosen as the subject of this study to investigate the paper's composition and structure using optical microscopy $(\mathrm{OM})$, SEM-EDS, X-ray photoelectron spectroscopy (XPS), Raman spectroscopy, and FTIR spectroscopy. The results revealed that the raw materials constituting the Lajian paper were bast and bamboo fibers. Each of the two paper layers was treated differently. First, the upper orange-red layer was treated with kaolinite and organic turmeric. Next, inorganic minium nt was used to obtain an orange-red color. Animal glue was used as a binding medium. Finally, the dyed surface was waxed with Chinese insect wax and then polished with small stones to form a smooth coating. The same treatment, except for the intentional use of inorganic pigment, was applied to the backing layer. Turmeric dye, minium, and wax coating protected Lajian paper from humidity and mold growth while maintaining the stability of the paper.
\end{abstract}

Keywords: Lajian paper, Manufacture, Orange-red, Non-destructive, Turmeric dyestuff

\section{Introduction}

An old Chinese saying states, "Paper lasts one millennium." As the birthplace of papermaking, China is the nation with the longest history of making traditional handmade paper. Over the centuries, papermaking technology has been constantly refined, and different papers have been produced for different purposes. Lajian paper-a very famous traditional handmade paper used primarily for imperial edicts, scripture, calligraphy, and painting-exhibits different colors, structure, and fine textures. Sometimes, the paper was decorated with gold or silver flecks for aesthetic effect, and these decorated papers were used by royal courts in ancient China. Lajian paper appeared in the Sui-Tang period and was produced widely during the Qing dynasty [1-3]. After waxing, the paper would be smooth, waterproof, anti-mildew, and insect-resistant. The use of this coating technology in

\footnotetext{
*Correspondence: luoybs@126.com

${ }^{1}$ School of History and Culture, National Center for Experimental Archaeology Education, Sichuan University, Chengdu 610064, China Full list of author information is available at the end of the article
}

China precedes the technology's use in Europe by more than 1000 years. However, the ancient method of making ancient Lajian paper has disappeared because of its time-consuming, painstaking nature, and the emergence of modern mechanical techniques at the end of the Qing dynasty [2-4]. Fortunately, some museums and private collectors in China still have some Lajian paper as well as Chinese calligraphy and paintings that have Lajian as the base material.

As Lajian is a famous traditional handmade paper that is an important part of China's cultural heritage, concerns have been raised about the manufacture of Lajian paper in recent years [2-5]. Some people have attempted to reconstruct the traditional technique; however, these attempts have not yielded very satisfying results because of a lack of comprehensive and scientific understanding of the paper's production process until now. It has been reported that Lajian paper manufacturing typically included coloring and waxing the paper to form a coating that protected it from humidity and mold growth [2-4]. The results of our previous analysis in which a piece of single-layered pink Lajian paper was examined revealed 
that the paper's composition and structure differed slightly from assumptions derived from traditional folklore [6]. Our previous study indicated that single-layered Lajian paper was produced from bamboo fibers mixed with wheat and mulberry fibers. The front of the paper was manufactured with kaolin and then polished with wax that was mixed with cochineal dye, minium, and animal glue to form a purple-red color. The same treatment, except for the use of cochineal dye, was administered to the back.

A single case study cannot represent the multifarious nature of Lajian paper. For a deeper understanding of both the manufacturing process and the materials used in Lajian paper manufacturing, we examined a small piece of orange-red Lajian paper with silver and gold flakes (Fig. 1). The paper's structure and appearance differ from those of our previous sample [6]. In this study, we analyze the structure and composition of the Lajian paper using non-invasive and micro-destructive multi-analytical approaches, such as optical microscopy, SEM, XPS, Raman, ATR-FTIR, and SERS spectroscopy.

\section{Experimental}

\section{Materials}

A small piece of orange-red Lajian paper $(1.5 \mathrm{~cm} \times 2 \mathrm{~cm})$ decorated with small flecks of silver and gold on the top layer (Fig. 1) and dating from the Qing dynasty was provided by the Sichuan Museum. Visual observation revealed that the Lajian paper was constructed from two layers of paper.

Very small segments of dyed fibers were extracted from the Lajian paper to conduct fiber characterization and SERS analysis. To minimize the risk of damage to the paper, partially protruding or detached fibers were extracted from the edge of the paper.

\section{Cross-section sample preparation}

Cross-section samples were selected and mounted in methacrylate light-curing embedding resin (Technovit ${ }^{\circledR}$ 2000 LC + ) and cured in a blue light "oven" (Technotray $\mathrm{CU} /$ Heraeus Kuler, Germany). The cross-section surface was polished by hand with Micro-Mesh polishing cloths of various grades up to the smallest, 12,000 grit (Micromesh, USA).

\section{Sample treatment for SERS procedure}

Silver colloids were prepared using microwave-assisted reduction of $\mathrm{Ag}_{2} \mathrm{SO}_{4}$ in the presence of glucose and sodium citrate [7]. Samples of concentrated colloids were prepared for SERS analysis by centrifuging the colloid solution and replacing it with ultrapure water.

\section{Characterization}

The fibers' structural and compositional characterizations were determined according to the procedures described previously [6].

\section{SEM-EDS examination}

The paper's micro-structure and elements were characterized using a high-resolution Hitachi Fields S-4800 SEM micro-analysis instrument equipped with EDS for elemental analysis; the machine was operated at $5 \mathrm{kV}$. The cross-sectional samples were obtained by cooling samples in liquid nitrogen for $10 \mathrm{~min}$ and immediately breaking the frozen sample. All samples were sputtercoated with carbon.
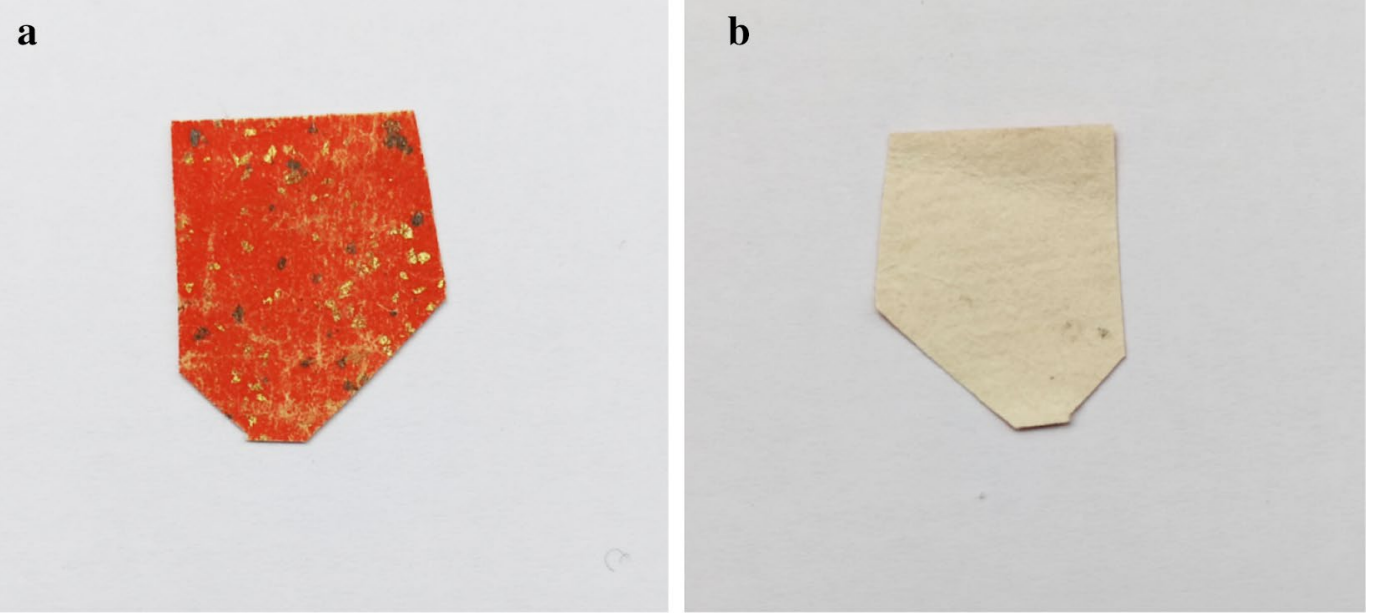

Fig. 1 Lajian paper sample with Au/Ag flakes and upper orange-red layer (a) and backing layer (b) 


\section{Optical microscopy (OM) observation}

Cross-section photomicrographs were captured using a Zeiss Axiotch $100 \mathrm{HD}$ polarizing microscope under ultraviolet and white reflected light at different magnification levels.

\section{$X$-ray photoelectron spectroscopy experiments}

X-ray photoelectron spectroscopy (XPS) measurements were obtained using an ESCALAB Mark II X-ray photoelectron spectrometer (XPS, VG Scientific, UK) in an ultrahigh vacuum. $\mathrm{Mg} \mathrm{K \alpha}(1253.6 \mathrm{eV})$ radiation was utilized as the excitation source. High-resolution scans of core-level spectra were set to $15 \mathrm{eV}$ of pass energy and recorded with an energy step of $0.05 \mathrm{eV}$. The binding energy was corrected by referencing the $\mathrm{C} 1 \mathrm{~s}$ peak at $284.6 \mathrm{eV}$.

\section{Raman spectroscopy}

A Bruker Senterra ${ }^{\mathrm{TM}}$ dispersive Raman spectrometer was used to perform micro-Raman spectroscopy. The instrument was operated at $785 \mathrm{~nm}$ with an integration time of $30 \mathrm{~s}$ and resolution of $3-5 \mathrm{~cm}^{-1}$. The laser beam was focused with a $50 \times$ long working distance objective; the surface laser power was limited to $1 \mathrm{~mW}$ to avoid not only degradation or heat-induced physical changes to the paper sample, but also heat-induced decomposition of lead white in case the latter was used as a coating pigment. Spectra were acquired and processed using OPUS 7.0 Raman software.

\section{ATR-FTIR analyses}

ATR-FTIR measurements were performed using a Thermo Nicolet iZ10 FTIR spectrophotometer equipped with a Thermo-Nicolet iN10 infrared imaging microscope. All samples were analyzed with a smart orbit single reflection diamond attenuated total reflectance (ATR) mode from 4000 to $650 \mathrm{~cm}^{-1}$ for 128 scans with $4 \mathrm{~cm}^{-1}$ spectral resolution. The FTIR microscope was equipped with an internal pressure sensor, a precise motorized $\mathrm{X}-\mathrm{Y}$ state, and an MCT detector, and was cooled with liquid nitrogen. ATR correction was not applied to the measured FTIR spectra before analysis.

\section{SERS measurements of organic dye on paper}

Samples for SERS analyses were obtained by removing fragments of single color fibers $(\sim 100 \mu \mathrm{m}$ in length) from the paper using a tungsten needle. The samples were analyzed following a multistep approach described previously [6, 7]: (1) selected paper fibers were briefly placed in a polyethylene micro-vial cover and then exposed to HF vapor. (2) After approximately
$5 \mathrm{~min}$, a $2 \mu \mathrm{l} \mathrm{Ag}$ colloid was deposited on the sample, followed by $0.4 \mu \mathrm{l}$ of $0.1 \mathrm{~N} \mathrm{KNO}_{3}$ solutions to induce colloid aggregation.

SERS analysis was conducted by placing the micro-vial directly under the objective for observation using the previously mentioned Raman instrument. Spectra were acquired by exciting the specimen at $488 \mathrm{~nm}$ through a $20 \times$ long working distance objective microscope at a resolution of $3-5 \mathrm{~cm}^{-1}$ and integrating the signal twice for $15 \mathrm{~s}$. Laser power did not exceed $0.4 \mathrm{~mW}$.

\section{pH measurements}

$\mathrm{pH}$ measurements were conducted in accordance with Gomaa [8] using a flat-surfaced $\mathrm{pH}$ electrode (METTLER TOLEDO S400 instrument, Switzerland). A drop of distilled water was placed on the paper surface, and a $\mathrm{pH}$ electrode was placed on the paper. The results are represented as an average of five repetitions of this procedure.

\section{Results and discussion}

\section{Micro-structural and fiber characterization}

Cross-sectional photomicrographs of the Lajian paper were observed under white and UV light, as shown in Fig. 2. The paper exhibited the traditional multi-layer structure for Lajian papers according to traditional folklore [1-3]. The cross-section images exhibited a bright red color under white light (Fig. 2a) and stratigraphic color layers under UV illumination (Fig. 2b). The microphotograph, shown in Fig. $3 \mathrm{~b}$, revealed the following color layers from top to bottom (shows in the inner part): a thin varnish layer (A), an orange-red layer (B), a yelloworange layer $(\mathrm{C})$, a white layer $(\mathrm{D})$, and a light yelloworange layer (E) by fluorescence under UV illumination. The cross-section analysis revealed a varnish layer (A), a dyed orange-red layer (B), a colorless fiber layer (D), and two yellow-orange fiber layers $(\mathrm{C}$ and $\mathrm{E})$. The varnish layer indicated that the paper surface was likely waxcoated. The orange-red fiber layers are likely the result of pigment and dye application [9]. The uncolored fiber layer (between the two yellow-orange layers) may have resulted from the inability of the organic dye to entirely penetrate the paper. The back did not exhibit an orangered color, thereby indicating that each paper layer was treated differently. This result indicated that these colorants were added to the paper surface by brushing.

The SEM image (Fig. 3a) of the cross-section revealed that the thickness of the paper was approximately $100 \mu \mathrm{m}$. The thickness of the upper and lower layers was approximately 60 and $40 \mu \mathrm{m}$, respectively. Figure 3b shows some needle-like and flaked materials on the fiber surface. The EDS results indicated that the main elements for these needle-like materials were $\mathrm{C}$ and $\mathrm{O}$ (the atomic percentage was greater than $95 \%$ ); these results may be 

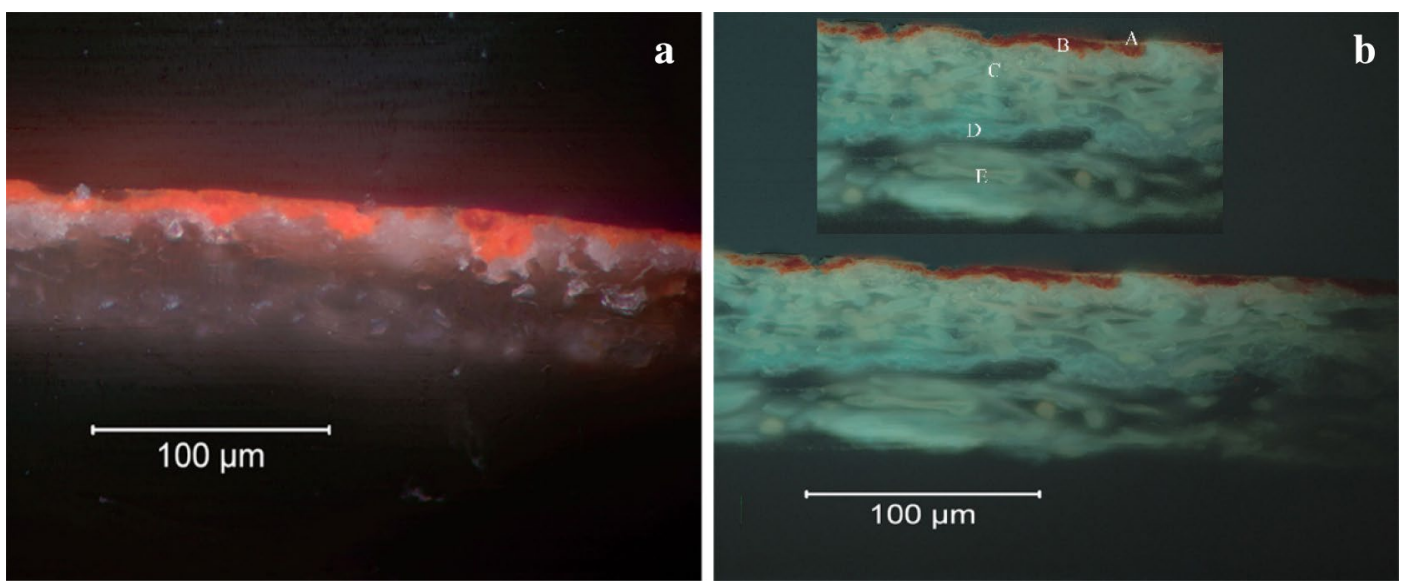

Fig. 2 Cross-sectional photomicrographs of the Lajian paper under $\times 50$ magnification. a Images under white light; $\mathbf{b}$ thin varnish layer (A), orange-red layer (B), yellow-orange layer (C), white layer (D), and light yellow-orange layer (E) by fluorescence under UV illumination
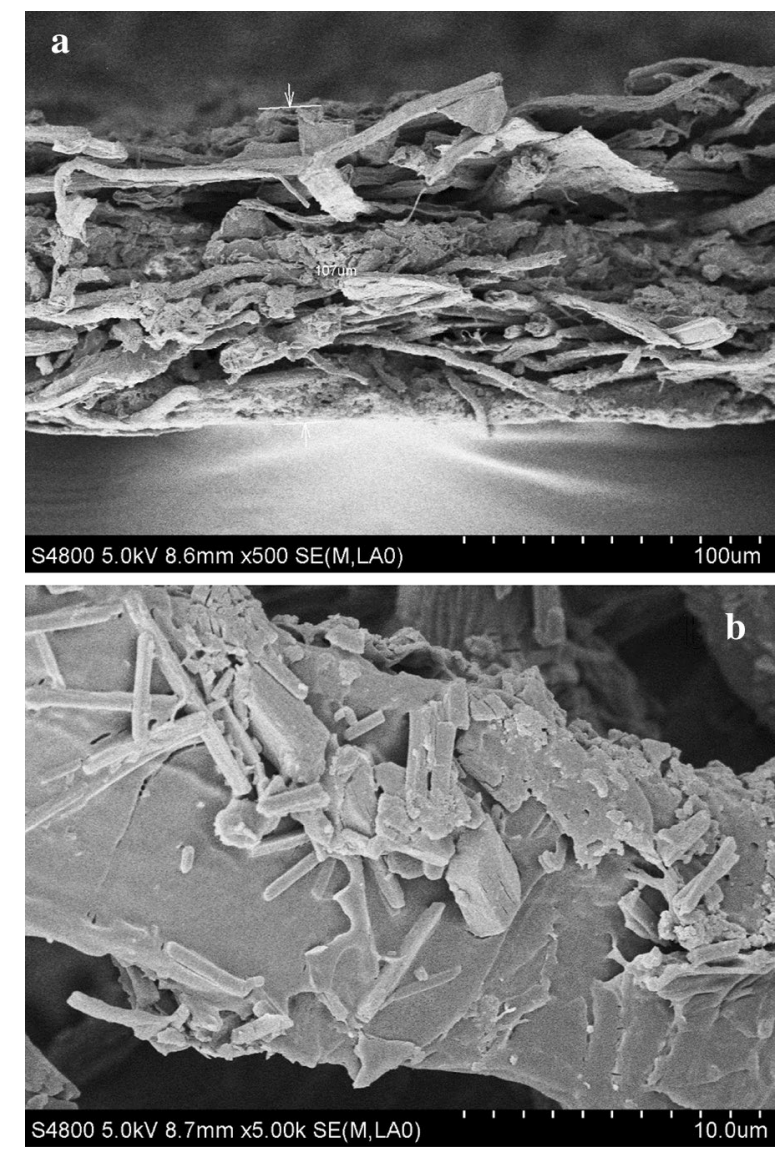

Fig. 3 SEM structure of cross-section. a Cross-section with ca. $100 \mu \mathrm{m}$ thickness $(\times 500)$, b some rod-like materials on the fiber surface $(\times 5000)$ ascribed to organic dyes. The flaked materials may be kaolinite $\left(\mathrm{Al}_{2} \mathrm{O}_{3} \cdot 2 \mathrm{SiO}_{2} \cdot 2 \mathrm{H}_{2} \mathrm{O}\right)$ as the main elements were $\mathrm{Al}, \mathrm{Si}$, and $\mathrm{O}$. According to SEM-EDS results, kaolinite may have been used as powder or coating pigment while needle-like material may have been used in dyes.

Figure 4 shows the micro-structure of the upper surface. Figure 5a shows that some cracks and holes were present on the surface. The holes indicated that some materials were peeled off from the upper surface; this peeling means that the coating materials did not bond well with the subsequent materials. This phenomenon was very similar to that shown in our previous findings on the pink single-layered Lajian paper [6]. Figure 4b shows irregular particles and a disrupted varnish layer on the upper surface. Almost no particles were found to be mixed with varnish, thereby indicating that the particles and varnish were applied to the upper surface separately. Needle-like materials were also found in these irregular particles in Fig. 4c under higher magnification. EDS analyses indicated that the major elements for the irregular particles included $\mathrm{Pb}, \mathrm{C}, \mathrm{O}, \mathrm{Al}$, and $\mathrm{Si}$. The presence of $\mathrm{Pb}$ indicated that minium $\left(\mathrm{Pb}_{3} \mathrm{O}_{4}\right)$ or lead white $\left[\left(\mathrm{PbCO}_{3}\right)_{2} \cdot \mathrm{Pb}(\mathrm{OH})_{2}\right]$ may have been used. The concurrent existence of $\mathrm{Al}$ and $\mathrm{Si}$ indicates the presence of kaolinite $\left(\mathrm{Al}_{2} \mathrm{O}_{3} \cdot 2 \mathrm{SiO}_{2} \cdot 2 \mathrm{H}_{2} \mathrm{O}\right)$. EDS analyses of the varnish indicated that the main elements were $\mathrm{C}$ and $\mathrm{O}$ (atomic percentage exceeded 98\%). The X-ray excitation depth was only 2-3 $\mu \mathrm{m}$ under an accelerating voltage of $5 \mathrm{kV}$. As such, the varnish was likely composed of wax. SEM results implied that a mixture of kaolinite, inorganic pigment, and organic dye was used as coloran to obtain an orange-red color, and that wax was coated on the whole upper surface separately. This result highlighted the need for further studies of mixed organic and inorganic 

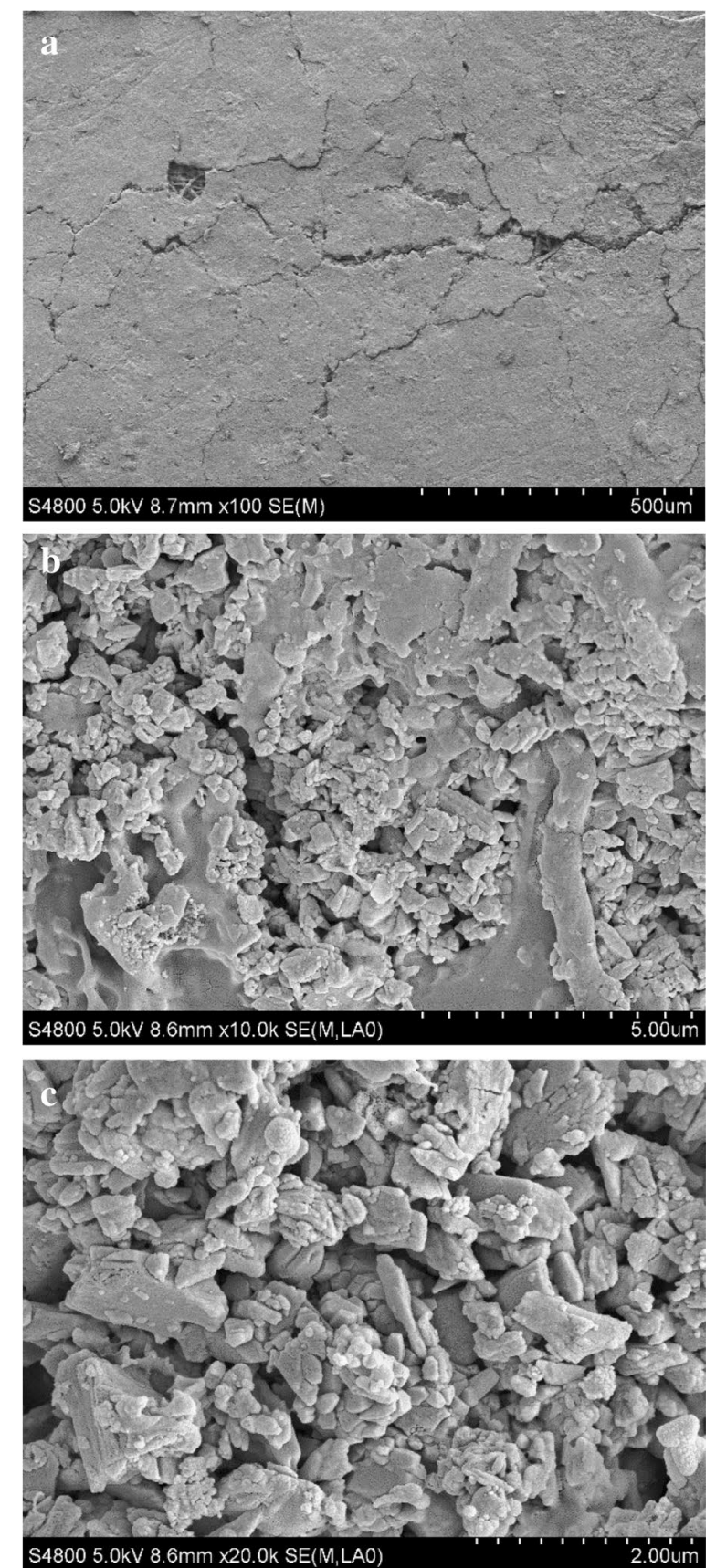

Fig. 4 SEM microstructure of upper surface. a Upper surface $(\times 100)$, b upper surface $(\times 10,000)$, c upper surface $(\times 20,000)$

components to comprehensively understand Lajian paper.

Traditional Chinese paper was made from plant fibers. Optical and microscope identification are effective tools for identifying fiber morphology [10-15]. Figure 5 shows the fiber structure under SEM observation. SEM images showed long tubular fibers with uneven surfaces and holes or crevices. Bast fibers typically exhibit these

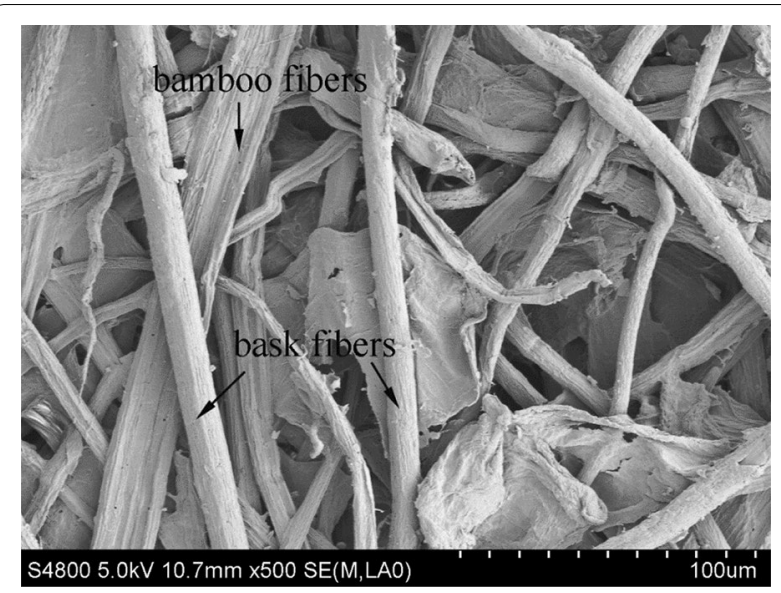

Fig. 5 SEM microscope of fibers

characteristics $[10,11]$. Other fibers with many shallow grooves may be bamboo fibers $[10,11]$. According to SEM test, the raw materials used in the Lajian paper are likely bast fiber and bamboo fiber, which were the characteristic components of traditional Chinese paper with significant consistency and strength.

In the second layer, no orange-red colorants were clearly observed under UV illumination, and no $\mathrm{Pb}$ and $\mathrm{Al}$ elements were detected by SEM-EDS. The light yellow-orange paper fibers observed under white light may be ascribed to organic dye. Both layers exhibited the same fiber morphology observed using SEM and OM. Figure 6 shows the wax coated back paper surface. Some fibers were mixed with wax, thus indicating that the second layer was not filled before being dyed. Thus, the production process for the second layer of Lajian paper involved treating the layer with organic dye and coating the layer with wax.

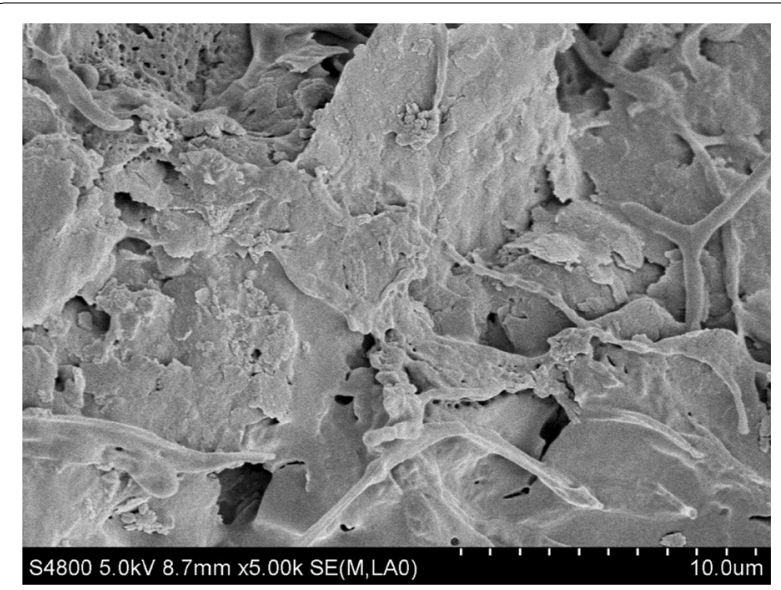

Fig. 6 SEM microstructure of backing layer 


\section{Spectral characterization}

XPS, a notably sensitive analytic method, was performed on the Lajian paper to obtain more information on the chemical composition of its surface. Figure 7 shows that the main elements of the first layer included $\mathrm{C}, \mathrm{O}, \mathrm{N}, \mathrm{Pb}$, $\mathrm{Al}$, and Si. The absence of Ag and Au may be due to the uneven distribution of flakes on the upper surface. The appearance of $\mathrm{N}$ implied that animal glue or gelatin may have been used as a binder. The appearance of $\mathrm{Pb}, \mathrm{Al}$, and Si was consistent with the SEM-EDS results and is likely ascribed to the presence of minium and kaolinite.

Raman spectroscopy identified pigments highly efficiently and non-destructively. The Raman spectral analysis of the first layer (Fig. 8) exhibited peaks at 122 vs, $152 \mathrm{~m}, 224 \mathrm{w}, 314 \mathrm{w}, 392 \mathrm{w}, 480 \mathrm{vw}$, and $550 \mathrm{vs} \mathrm{cm}^{-1}$; these peaks levels were attributed to the vibrational modes of $\mathrm{Pb}-\mathrm{O}$ bonds $[16,17]$ and are characteristic of minium $\left(\mathrm{Pb}_{3} \mathrm{O}_{4}\right)$. However, there was no evident signal for $\mathrm{PbCO}_{3}, \mathrm{PbO}$, or $\mathrm{PbO}_{2}$. Minium commonly occurs in small amounts as a bright red or orange powder [18], and it was widely used as a red and orange pigment in ancient China. This result indicated that minium was intentionally sprayed on the upper surface and remained stable over time in the Lajian paper sample.

ATR-FTIR analyses were used to identify unknown organic materials on the upper surface (Fig. 9). The broad absorption at $3369 \mathrm{~cm}^{-1}$ was attributed to the stretching vibration of hydroxyl groups $(\mathrm{O}-\mathrm{H})$ and $\mathrm{N}-\mathrm{H}$ groups. Significant bands at 2869 and $2949 \mathrm{~cm}^{-1}$ were identified as methyl and methylene groups. The vibrations at $1150 \mathrm{~cm}^{-1}$ and $1058 \mathrm{~cm}^{-1}$ could be assigned to $\mathrm{C}-\mathrm{O}-\mathrm{C}$ and $\mathrm{C}-\mathrm{O}$ stretching, respectively [19]. Bands at $1600 \mathrm{~cm}^{-1}$ (stretching amide I), $1540 \mathrm{~cm}^{-1}$ (stretching amide II absorption, combination of $\mathrm{C}-\mathrm{N}$ stretching

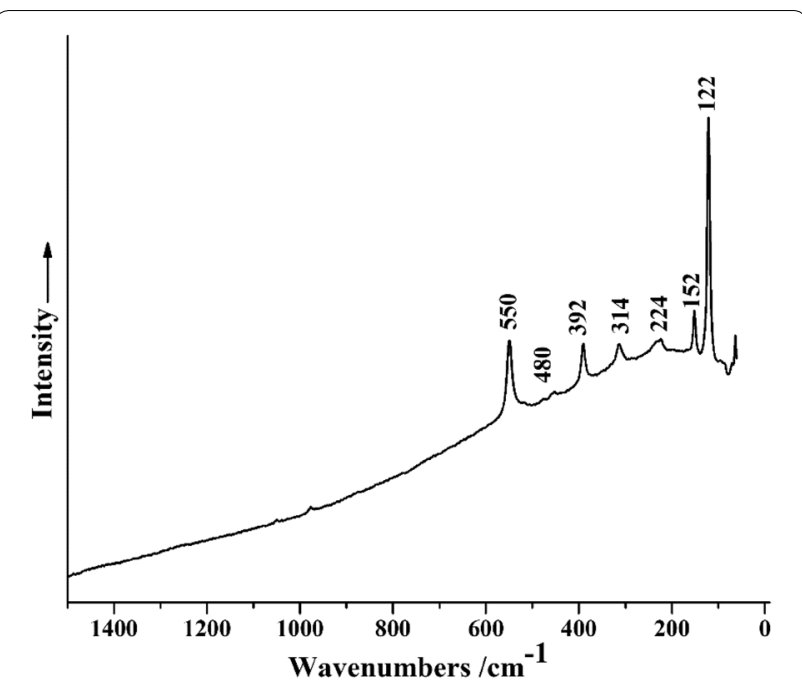

Fig. 8 Raman spectra of the orange-red layer

and $\mathrm{NH}$ bending), and $1455 \mathrm{~cm}^{-1}$ (amide III absorption, $\mathrm{C}-\mathrm{N}$ stretching/bending) may be attributed to animal glue (gelatin) [19-21]. Traditionally, in ancient China, glue was added to a dyed solution to obtain a uniform color [22, 23]. Therefore, animal glue may have been used as glue during the dyeing process. It has been reported [24] that introducing pigment to animal glue resulted in splitting the amide II band into two components. ATRFTIR analyses revealed that the band at $1540 \mathrm{~cm}^{-1}$ was split into 1542 and $1523 \mathrm{~cm}^{-1}$; this split was attributed to a change in the protein structure because of the effects of minium or kaolinite coating pigments. The bands at $921 \mathrm{~cm}^{-1}$ and $885 \mathrm{~cm}^{-1}$ were characteristic for the stretching mode of Al-O. Combining the strong band at

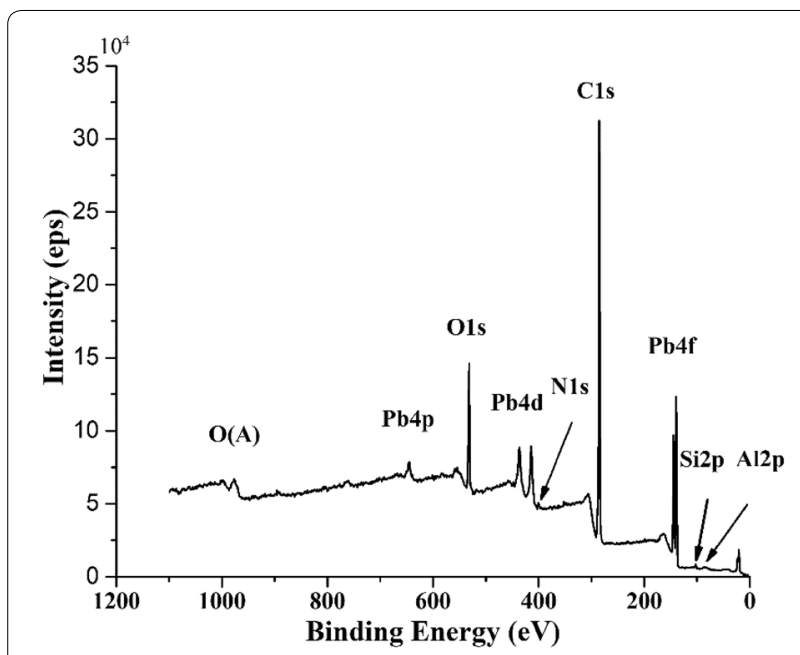

Fig. 7 XPS spectroscopy of the orange-red layer

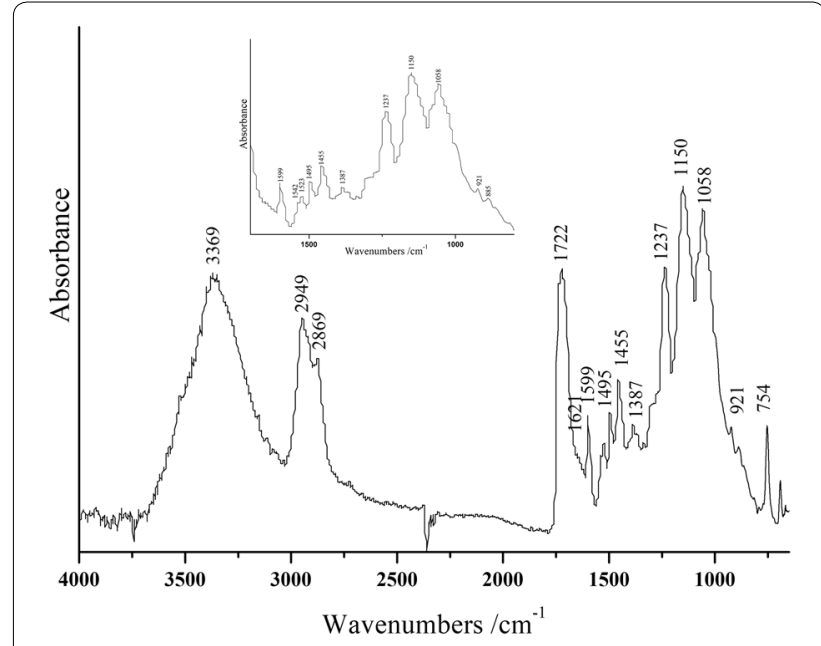

Fig. 9 ATR-FTIR of the orange-red layer 
$1058 \mathrm{~cm}^{-1}$ and the SEM-EDX results may confirm the use of kaolinite during the papermaking process. The notably strong band at $1722 \mathrm{~cm}^{-1}$ is characteristic of the carbonyl group vibration $(\mathrm{C}=\mathrm{O})$, thus indicating that the organic colorant or glue may have carbonyl groups.

SERS was conducted and spectra were obtained from the paper fibers. Figure 10 reveals peaks at 1577, 1532, $1468,1230,1194,1130,1101,1052,1011,455$, and $414 \mathrm{~cm}^{-1}$; these peak levels were consistent with the literature [25] and could be ascribed to curcumin, the main component of turmeric. These results coincided with those obtained from the ATR-FTIR of turmeric (approximately at $\left.1621,1599,1237,1150 \mathrm{~cm}^{-1}\right)[19,26]$. The bands at $1722 \mathrm{~cm}^{-1}$ could be ascribed to Chinese insect wax, according to the ATR-FTIR results. It was reported that Chinese insect wax, which had carboxyl groups, was used widely to produce Lajian paper to form bright white coating in ancient China $[3,4]$.

Natural organic dyes and their corresponding lake pigments were important materials in the artist's palette from ancient times until the second half of the nineteenth century, when the industrial production of synthetic dyes began. Turmeric-which is made from the rhizome of Curcuma longa L. (family Zingiberaceae)-is a main ingredient of curry powders. Turmeric is well known for its color, flavor, and digestive properties. Some researchers have reported that turmeric was used as a dye in ancient China [27-29]. Curcumin is the main colorant in turmeric, which is used to produce yellow-orange colorants. Previous research demonstrated that turmeric was typically stable, $\mathrm{pH}$ sensitive, and exhibited a yellow, red, or dark orange color under acidic, alkaline, or neutral conditions, respectively [30].

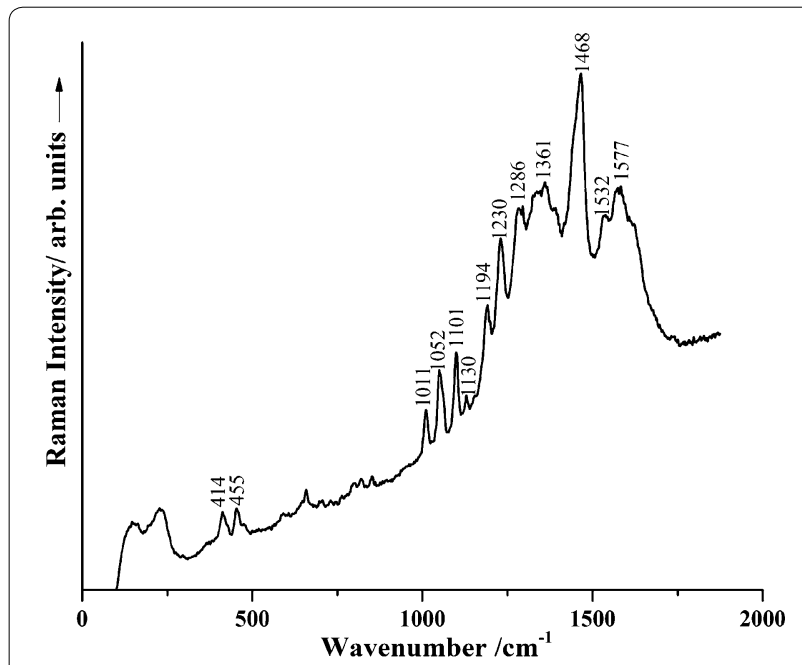

Fig. 10 SERS spectra of the turmeric dyes (spectruma is obtained from a single fiber in the Lajian paper)
The paper acidity test showed that the $\mathrm{pH}$ value of the paper surface was 7.1-7.4. This is why the organic dyestuff exhibited a dark orange color under UV illumination (Fig. 2). Likewise, Suo [30] reported that turmeric dye has a needle-like micro-structure, as shown in Figs. 3 and 4. According to these results, turmeric may be confirmed as an organic dye in Lajian paper.

\section{Conclusions}

In this study, a small piece of orange-red Lajian paper dating from the Qing dynasty was evaluated by combining SERS microanalysis with non-destructive and microdestructive SEM, XPS, micro-Raman, and ATR-FTIR techniques. Micro-observations revealed that the raw fiber materials were bast fiber mixed with bamboo fiber. The evidence derived from SEM, XPS, Raman, ATRFTIR, and SERS analyses demonstrated that minium and turmeric dyes were used as colorants to obtain an orange-red color while kaolinite might have been used as a coating pigment. The process used for the upper layer of the Lajian paper may have included (in sequence) dyeing the paper by brushing coating pigment and organic dyes on the surface, brushing inorganic red pigment on the coated surface, waxing the paper with Chinese insect wax, and then polishing the surface to form a smooth wax coating. Animal glue was used as a binding medium during dyeing, but further experiments are needed to identify the type of animal glue. The same treatment, except for the intentional use of inorganic pigment, was applied to the backing layer. Neutral conditions are conducive to preserving this type of paper. The wax coating surface and turmeric and minium colorant could protect the paper from both humidity and mold growth.

\section{Abbreviations \\ OM: optical microscope; XRF: $X$ ray fluorescence spectroscopy; ATR-FTIR: attenuated total reflection flourier transformed infrared spectroscopy. \\ Acknowledgements \\ The authors gratefully acknowledge financial support from the High Level Research Team Building Plan of Social Sciences in Sichuan Province (Sichuan Federation of Social Science Association [2017] 43-2) and the Sichuan University Research Cluster for Regional History. Yanbing Luo gratefully acknowledges Marco Leona, the Director of Scientific Research Department of Metropolitan Museum of Art and his co-workers for their help and assistance with the Raman and SERS analyses during Yanbing's visiting scholar program} at MET.

\section{Authors' contributions}

Data were collected by YBL, JLC and YFH. YBL and CY prepared and revised the manuscript. All authors read and approved the final manuscript.

\section{Funding}

The research was supported by the Science \& Technology Program of Sichuan, China under Grant 2019YFS0494; the Key Projects of Social Science Planning in Sichuan Province under Grant SC18A013. 


\section{Availability of data and materials}

The datasets used and/or analysed during the current study are available from the corresponding author on reasonable request.

\section{Competing interests}

The authors declare that they have no competing interests.

\section{Author details}

1 School of History and Culture, National Center for Experimental Archaeology Education, Sichuan University, Chengdu 610064, China. ${ }^{2}$ College of Chemistry, Sichuan University, Chengdu 610064, China. ${ }^{3}$ Sichuan Museum, Chengdu 610105, China.

Received: 28 May 2019 Accepted: 9 August 2019

Published online: 15 August 2019

\section{References}

1. Zhang XG. The restoration of imperial edict of Zhengtong Emperor and wax paper cultural relics in Ming Dynasty. Wuhan Cult Mus. 2013;2:33-6.

2. Guo WL, Zhang XW, Zhang XG. The research and replication of Lajian paper in Qing Palace. Palace Mus J. 2004;6:145-58.

3. Liu RQ. Studies on the white power and wax paper-the fourth part of research addendum of ancient paper. Paper Papermak. 2015;34(5):85-8.

4. Jin $\mathrm{YH}$. Research on dyeing technology of ancient paper in China. Master Thesis: University of Science and Technology Beijing, China; 2012.

5. Gao XM. Material selection and restoration of powder wax paper. Wax paper for paper-based paintings and calligraphy in the Summer Palace Hall. The collection of the fifth academic conference of the Beijing Museum Society. 2007. p. 500-6.

6. Luo YB, Wang Y, Zhang XJ. A combination of techniques to study Chinese Traditional Lajian Paper. J Cult Herit. 2019;56:78. https://doi.org/10.1016/j. culher.2019.01.008.

7. Casadio F, Leona M, Lombardi JR, Duyne RV. Identification of organic colorants in fibers, paints, and glazes by surface enhanced Raman spectroscopy. Acc Chem Res. 2010;43(6):782-91.

8. Abdel-Maksoud G. Analytical techniques used for the evaluation of a 19th century quranic manuscript conditions. Measurement. 2011:44(9):160617. https://doi.org/10.1016/j.measurement.2011.06.017.

9. Oakley LH, Dinehart SA, Svoboda SA, Wustholz KL. Identification of organic materials in historic oil paintings using correlated extraction less surface-enhanced Raman scattering and fluorescence microscopy. Anal Chem. 2011;83:3986-9. https://doi.org/10.1021/ac200698q.

10. Wang JH. Papermaking raw materials of China_an atlas of micrographs and the characteristics of fibers. Beijing: China Light Industry Press; 2007.

11. Liu C, Li XC, Wang S, Zhang XY. A study on the relevance of paper age according to fiber species. Chin Paper-Mak. 2013;32(8):63-8.

12. Yi XH. Fibrous raw material taxonomies of Chinese ancient paper and traditional handmade paper. China Pulp Paper. 2015;34(10):76-80.

13. Li T. Technical investigation of ancient Chinese paper based material with now-destructive chemical methods. PhD thesis. Beijing: Graduate University of Chinese Academy of Sciences; 2010.

14. Ilvessalo-Pfäffli MS. Fiber atlas: identification of papermaking fibers. In: Timell TE, editor. Springer series in wood science. Berlin: Springer; 1995.

15. Catling D, Grayson J. Identification of vegetable fibres. New York: Chapman and Hall Ltd.; 1982

16. Trettenhahn GLJ, Nauer GE, Neckel A. Vibrational spectroscopy on the $\mathrm{PbO}-\mathrm{PbSO}_{4}$ system and some related compounds: Part 1. Fundmentals, infrared and Raman spectroscopy. Vib Spectrosc. 1993;5:85-100. https:// doi.org/10.1016/0924-2031(93)87058-2.

17. Dan AC, Clark RJH, Mcdonald LJ, Odlyha M. Studies on the thermal decomposition of basic lead (II) carbonate by Fourier-transform Raman spectroscopy, X-ray diffraction and thermal analysis. J Chem Soc Dalton Trans. 1996:35:3639-45. https://doi.org/10.1039/dt9960003639.

18. Eastaugh N, Walsh V, Chaplin T, Siddall R. The Pigment Compendium: a dictionary of historical pigments. London: Routledge; 2004.

19. Beltran V, Salvadó N, Butí S, Cinque G. Micro infrared spectroscopy discrimination capability of compounds in complex matrices of thin layers in real sample coatings from artworks. Microchem J. 2015;118:115-23. https://doi.org/10.1016/j.foodchem.2017.06.022.

20. Maier SM, Parera SD, Seldes AM. Matrix-assisted laser desorption and electrospray ionization mass spectrometry of carminic acid isolated from cochineal. Int J Mass Spectrom. 2004;232(3):225-9. https://doi. org/10.1016/j.ijms.2003.12.008.

21. Ahmed H, Mohamed W, Saad H, Nasr H, Morsy M, Mahmoud N. Degradation behavior of nano-glue adhesive due to historical textiles conservation process. Egypt J Chem. 2017;60(6):1-12. https://doi.org/10.21608/ ejchem.2017.1455.1105.

22. Tong ZZ. Restoration techniques for Chinese ancient book. Shanghai: Shanghai Chinese Classics Publishing House; 2014. p. 42

23. Casoli A, Isca C, De lasio SD, Botti L, lannuccelli S, Residori L, Ruggiero D, Sotgiu S. Analytical evaluation, by GC/MS, of gelatine removal from ancient papers induced by wet cleaning: a comparison between immersion treatment and application of rigid Gellan gum gel. Microchem J. 2014;117:61-7. https://doi.org/10.1016/j.microc.2014.06.011.

24. Dallongeville S, Garnier N, Rolando C, Tokarski C. Proteins in art, archaeology, and paleontology: from detection to identification. Chem Rev. 2016;116(1):2-79. https://doi.org/10.1021/acs.chemrev.5b00037.

25. Mayhew HE, Fabian DM, Svoboda SA, Wustholz KL. Surface-enhanced Raman spectroscopy studies of yellow organic dyestuffs and lake pigments in oil paint. Analyst. 2013;138:4493-9.

26. Er SV, Eksi-Kocak H, Yetim H, Hasan Yetim H, Boyaci IH. Novel spectroscopic method for determination and quantification of saffron adulteration. Food Anal Methods. 2017;10(5):1547-55.

27. He XG, Lin LZ, Lian LZ, Lindenmaier M. Liquid chromatography-electrospray mass spectrometric analysis of curcuminoids and sesquiterpenoids in turmeric (Curcuma longa). J Chromatogr A. 1998;818:127-32. https:// doi.org/10.1016/s0021-9673(98)00540-8.

28. Gad HA, Bouzabata A. Application of chemometrics in quality control of turmeric (Curcuma longa), based on ultra-violet, Fourier transforminfrared and 1H NMR spectroscopy. Food Chem. 2017;237:857-64. https ://doi.org/10.1016/j.foodchem.2017.06.022.

29. Bruni S, Guglielmi V, Pozzi F. Historical organic dyes: a surface-enhanced Raman scattering (SERS) spectral database on Ag Lee-Meisel colloids aggregated by $\mathrm{NaClO}_{4}$. J Raman Spectrosc. 2011;42(6):1267-81. https:// doi.org/10.1002/jrs.2872.

30. Suo QL, Huang YC, Weng LH, He WZ, Li CP, Li YX, Hong HL. Study on purification and molecular crystal structure of natural curcumin. Food Sci. 2006;27(3):27-30.

\section{Publisher's Note}

Springer Nature remains neutral with regard to jurisdictional claims in published maps and institutional affiliations. 